\title{
A CONTRIBUCIÓN DE CARBALLO CALERO Á CANONIZACIÓN DA LITERATURA GALECA
}

\author{
THE CONTRIBUTION OF CARBALLO CALERO \\ TO THE CANONIZATION OF GALICIAN LITERATURE \\ Dolores Vilavedra \\ Universidade de Santiago de Compostela
}

\begin{abstract}
Resumo: Este artigo tenta definir os criterios aplicados por Carballo Calero, ao longo do seu extenso labor como crítico e investigador, na avaliación e canonización do corpus narrativo galego. Por medio dunha revisión panorámica e non exhaustiva da súa produción ensaística procurarase trazar a orixe deses criterios, os elementos operativos na súa formulación como tales e o resultado da súa aplicación. Analizaranse algúns casos de obras e autores concretos e, por último, atenderase á evolución deses criterios e ás consecuencias desta na valoración de certas obras e modalidades narrativas.
\end{abstract}

Abstract: This article aims to delineate the criteria applied by Carballo Calero to the evaluation and canonization of the Galician narrative corpus across his extensive output as a critic and researcher. Through a panoramic (though non-exhaustive) review of his essays, the origin of the criteria and the concepts at play in their formulation, as well as the result of their application, shall be assessed. Some cases of specific writers and works are then analysed. Finally, an account of the evolution of these criteria and their impact on the evaluation of certain works and narrative modes is provided.

Palabras chave: Ricardo Carballo Calero, narrativa, canon, historia da literatura Key words: Ricardo Carballo Calero, narrative, canon, literary history. 


\section{UNHA OLLADA PANORÁMICA}

O obxectivo destas páxinas é demostrar o escaso interese de Ricardo Carballo Calero (CC, de agora en diante) pola narrativa ficcional, tanto na súa faceta de creador coma na de investigador, e tentar avanzar algunhas hipóteses explicativas desta actitude, alén das súas lexitimamente subxectivas preferencias. Respecto á primeira -Carballo como autor de ficción narrativa-, na longa conversa mantida con Carmen Blanco en 1989 queda clara a súa consideración secundaria do xénero narrativo. Á pregunta da entrevistadora "¿Que se considera máis, poeta, narrador ou autor dramático? ¿En que xénero se atopa máis a gosto ou non pode realmente escoller?" (Blanco 1989, p. 237), a resposta de Carballo é cando menos sorprendente pois esténdese en consideracións sobre poesía e teatro e nin menciona a narrativa, ata o punto de que a entrevistadora lle ten que insistir inquirindo por "iE como se sente no molde narrativo?". Posto nesta tesitura, CC confesa con franqueza a súa preferencia polo relato curto e a súa escasa paciencia para acometer o que el mesmo denomina "unha novela propiamente dita", por mor da canseira que lle producen as "obras máis longas" (Blanco 1989, p 238). Con grande intelixencia e coherencia, Carballo vencella esa súa preferencia polas formas narrativas breves á tradicionalmente manifestada pola literatura galega, que el explica con argumentos socioculturais e económicos que non resultarán descoñecidos para quen coñeza os problemas que afectaron ao desenvolvemento do xénero xa dende as súas orixes:

Hai poucos apoios e poucas posibilidades editoriais, poucos leitores, por muito que se teña progresado nestes aspectos ultimamente. Neste sentido, se cadra, é unha literatura un pouco de urxencia, na que o poema lírico e o relato breve ou a novela curta teñen máis posibilidades de éxito. [...] unha novela longa como Os irmans Karamazov ou un Rouge et noire, exixe muito tempo de traballo e o escritor galego non sabe, cando comeza unha obra, se ao rematala terá editor, terá posibilidades de publicación, terá público que se interese por ela, e entón quizá estamos dominados pola necesidade de producir literatura de consumo imediato (Blanco 1989, pp. 239-240).

Pero centrémonos na obra investigadora de Don Ricardo. Dende as súas primeiras pescudas, $\mathrm{CC}$ establece un par opositivo de xinea formalista ${ }^{1}$ que distingue

1 Non hai practicamente investigacións sobre os modelos teóricos e historiográficos subxacentes á obra crítica de CC. Casas (2020, pp. 198-201) esboza unha posible xenealoxía da pegada que no seu pensamento deixaría a escola formalista soviética por medio da Teoría de la literatura de René Wellek e Austin Warren, cuxa tradución ao castelán apareceu en Gredos en 1953 e que de certo CC coñeceu e manexou. 
poesía / prosa, aplicando este segundo termo tanto á ficcional coma á non ficcional e integrando baixo esta etiqueta non só o ensaio senón tamén o teatro. Se estudamos polo miúdo o emprego desta terminoloxía na súa Historia da literatura galega contemporánea ${ }^{2}$ decatámonos de que, dentro da prosa, Don Ricardo reserva o campo semántico da novela e a narrativa para aqueles autores e obras que revelan xa unha certa competencia. O primeiro, como veremos, López Ferreiro. Este é un dato interesante porque amosa que, para Carballo, o recoñecemento da existencia dun xénero narrativo galego non é tanto unha cuestión cronolóxica, vencellada a unha hipotética madurez do xénero, coma derivada da demostración dun certo grao de elaboración e complexidade técnica e argumental que non estaría necesariamente relacionado cunha maior extensión, tal e como revela a análise das novelas -así chamadas por CC- de López Ferreiro. En 1975, cunha visión máis ampla e máis madura da evolución do xénero, CC mantense fiel a este criterio e formúlao con máis precisión ao recoñecer que, cando emprega o termo 'novela', inclúe nesa consideración "la novela breve, que no es una 'novela corta' sino una 'novela' de dimensiones reducidas" (Carballo 1975, p. 62).

Unha ollada ao índice da HLG amosa con claridade este criterio cualitativo subxacente ao seu manexo do par conceptual prosa / narrativa. Así, por exemplo, baixo o epígrafe "Prosistas da Irmandade da Cruña", Carballo trata non só a obra ensaística de Ramón Villar Ponte ou Viqueira senón a dramática de Antón Villar Ponte. Semellante carácter misceláneo ten o apartado "Outros poetas e prosistas continuadores da tradición", onde atende tanto a coleccións de contos ou relatos coma a pezas teatrais e, por suposto, poemarios. Todo isto despois de ter dedicado varias páxinas a López Ferreiro como o primeiro dos novelistas do século XIX.

Teremos ocasión de volver sobre a HLG ao longo destas páxinas. Se deitamos agora unha ollada panorámica a un conxunto significativo dalgunhas das obras misceláneas nas que Carballo compila os seus estudos, atopamos dúas evidencias relevantes para o tema que nos ocupa: unha, a escasa atención dedicada ao xénero; dúas, a alta consideración canónica que sempre lle mereceron Castelao, Otero e -nun segundo nivel- Risco. As obras narrativas dos dous primeiros autores serán as que capten maioritariamente a súa atención analítica e crítica.

Así, en Sobre lingua e literatura galegas (1971), dos tres bloques nos que se divide a obra (lingua, estudos medievais e literatura), o dedicado á literatura comprende dez traballos dos cales só un está dedicado á narrativa (A orella no buraco) e outro aos contos populares da provincia de Lugo.

Da fala e da escrita é un volume publicado en 1983 que recolle varios textos de amplo alento nos que CC reflexiona sobre temas como "As origens da literatura

2 De agora en diante, HLG; referirémonos sempre, como é habitual, á 3ª edición que data de 1981. 
galega contemporánea" e fai unha "Introduçom à história da literatura galega". Pois ben, en ningún destes dous longos artigos se menciona a existencia dunha produción narrativa galega, algo -na miña opinión- ben significativo da súa concepción 'secundarizada' do xénero: para Carballo, o xénero canónico da literatura galega é a poesía ${ }^{3}$. Que el saiba que esa posición canónica se explica por razóns sociohistóricas ${ }^{4}$ non abonda como para que sexa quen de subtraerse a unha convicción que orientará, como veremos, todo o seu labor crítico, tanto a prol da lírica coma en detrimento da atención prestada á narrativa.

A firmeza desa convicción explícase, na miña opinión, porque arrinca directamente dos principios formulados polos homes de Nós como bases substantivas da identidade galega. Como é sabido, eses principios son: lirismo, humorismo, sentimento da terra e saudade. A analizalos dedicarán boa parte dos seus esforzos investigadores (tamén creativos!) e conseguirán así desenvolver unha proposta tan sólida que será herdada, case sen solución de continuidade, polo grupo Galaxia como alicerce sobre o que erguer o seu proxecto editorial, no que desempeña un papel principalísimo -cómpre non esquecelo- Don Ricardo. Non abondaremos nesta cuestión, que nos afastaría dos nosos obxectivos, mais boa mostra de ata que punto esa ideas seguían a estar operativas nos 50 témola no artigo que Ramón Piñeiro publica en 1959 nun monográfico da revista Ínsula dedicado á literatura galega e significativamente titulado "Factores esenciales de la literatura gallega", no que segue a insistir en que estes son lirismo, humorismo e sentimento da paisaxe.

En Estudos e ensaios sobre literatura galega (1989), onde se recollen 38 estudos de distintos asuntos literarios, non hai ningún artigo dedicado á narrativa agás dous, moi significativos. O primeiro é unha recensión datada en 1986 e dedicada á antoloxía preparada por Kathleen March do conto literario galego; nela CC abonda no argumentario xa comentado a prol do éxito do conto literario como xénero narrativo galego. O segundo, datado en 1985, é unha análise de Amantia na que o profesor se centra na súa dimensión de 'romance histórico', un dato este que -como veremos- explica o seu interese pola novela. Pero alén deste par de

3 Son moi numerosas as súas manifestacións sobre esta cuestión. Velaquí algunhas das, se cadra, menos coñecidas: "La prosa no contaba con una tradición medieval tan ilustre como la poesía. Pero ello difícilmente puede explicar su inferir o desarrollo contemporáneo pues [...] la poesía trovadoresca fué desconocida de los primeros precursores, lo que no impidió la formación y consolidación de la lírica romántica" (Carballo 1955, p. 11) e "Non cabe dúbida que a máis valiosa aportación galega a creación literaria é a lírica" (Lorenzana 1955, p. 4). Ou a invisibilización da globalidade do xénero narrativo galego que supón que os únicos narradores que menciona nunha conferencia impartida en 1971, titulada "Figuras representativas da literatura galega actual” (Carballo 1974), sexan Otero e Castelao (unha vez máis!).

4 "De İtaca a Rianxo" (datado en 1980, cítase pola versión recollida en Carvalho 1992, p. 54): "Son as circunstáncias historicas as que explican o florecimento dos xéneros e das linguas. Se Galiza fose un país próspero, falaríamos menos, se cadra, de saudade e lirismo". 
traballos especificamente dedicados a obras narrativas, interésame agora desviar un chisco a ollada cara ao texto titulado "A obra literária de Castelao". Por que? Pois porque en 1986, ano no que está datado este artigo, CC non só segue a apostar polo rianxeiro como autor de referencia senón que toda a súa análise e a súa valoración continúan a xirar arredor de dous argumentos que a quen seguise o discurso crítico do profesor lle deberían soar daquela ben coñecidos ${ }^{5}$ : un, que toda a produción narrativa de Castelao se constitúe como desenvolvemento da estrutura cousa, é dicir, a idea de que as formas breves son o xermolo tamén das súas novelas; dous, a dimensión musical das narracións do rianxeiro, o que de certo as aproximaba á poesía e, por tanto, ao xénero máis canonicamente galego. Como mostra, estas palabras:

Castelao, mui afeiçoado à música, elabora cuidadosamente a frase, procurando un ritmo límpido, con cadências melódicas mui acusadas. A fluência do seu estilo, con freqüentes paralelismos, reiteraçons e antinomias, envolve nas suas odas de harmonia, umha consideraçom sentimental do mundo galego, que descreve com um lirismo atemperado polo humor (Carballo 1989, p. 233).

De novo, brevidade, humor e lirismo como marcadores de galeguidade e, xa que logo, a asunción por parte de CC da proposta de Nós como marco de referencia identitario.

En Do galego e da Galiza (1990) CC só presta atención a outro dos seus narradores de referencia, neste caso Otero Pedrayo. Botemos unha ollada ao texto titulado "Otero Pedrayo na história do romance galego". Aquí Carballo ten que dar un pinchacarneiro argumental prodixioso para beirear o feito de que Don Ramón é o primeiro gran novelista galego, unha evidencia que lle custa recoñecer explicitamente. E como fai? Pois acolléndose á súa tan gabada condición de polígrafo, que o levaría a non distinguir "com exactitude os limites que separam os diversos géneros literários" (Carvalho 1990, p. 179) ata o punto de que "às vezes en presença das suas obras, nom podemos dizer se se trata de trabalhos de tipo épico, se se trata de trabalhos de tipo lírico, se se trata de obras de carácter dramático" (1990, p. 180); o que lle permite afirmar, un tanto arbitrariamente, que "Devalar, que tem umha estrutura externa de romance, é na realidade um poema" (1990, p. 180). Porén, consciente "do papel que no decurso da história do romance galego Otero representa" (1990, p. 188), CC vese obrigado a argumentar a prol desa posición de privilexio. Faino, por unha banda, cun argumento cuantitativo ("Hai,

5 Por exemplo, en 1974 manifesta que "Lirismo e humorismo son as chaves da arte de Castelao" (Carballo 1974, p. 277). 
pois, em Otero Pedrayo um romancista importante [...] embora non seja mais que polo feito de que el escreveu mais obras narrativas, longas e breves, que qualquer outro escritor galego", 1990, p. 187) que hoxe semella, como pouco, inxenuo mais que pode e debe entenderse na lóxica imperante no proceso histórico de desenvolvemento da literatura galega, polo que non imos deternos nel. Por outra banda, CC valora extraordinariamente (emprego palabras súas) a obra narrativa de Otero porque "tem na realidade um protagonista único, que é a nossa terra, que é Galiza” (1990, p. 185), argumento respectable mais non exclusivo do xénero narrativo. A seguir, CC repara aínda na capacidade de Don Ramón para elaborar unha "história épico-lírica de Galiza" (1990, p. 194): a lírica, sempre como valencia positiva.

Algo semellante acontece en Umha voz na Galiza (1992) onde apenas 4 dos 101 artigos que se recollen no volume están centrados na faceta narrativa de dous autores de referencia, López Ferreiro e Risco. Volveremos sobre o primeiro e, en canto ao segundo, CC gaba a súa narrativa de novo (como acabamos de comentar para o caso de Otero) con argumentos que teñen máis que ver coa súa potencia ideolóxica e menos cunha eficaz resolución como relatos literarios. Así, afirma que "as suas obras [de Risco] mais importantes de ficción son tamén testemuños explícitos do seu pensamento" (Carvalho 1992, p. 155) nas que "está ausente o propósito de criar personaxes dotados da complexa individualidade dos seres humanos reais. Os actantes o caracteres, monifates que representan unha ideologia, ou unha forma de vida social" (1992, p. 156).

Este mesmo marco conceptual que explica a secundaria posición que CC lle outorga ao xénero narrativo na historia da literatura galega explica tamén a alta consideración que lle merecían as novelas de López Ferreiro que xulga marcan "un fito" (Carballo 1979, p. 225) polo seu carácter pioneiro ("As novelas de López Ferreiro son das primeiriñas escritas en galego moderno", 1979, p. 227), pola utilidade da súa lectura para "os aprendices de galego" (1979, p. 229) pero, sobre todo, "como documentos histórico-sociáis [que achegan] moita información sobre as relacións entre os diversos estamentos que constituían no pasado a sociedade galega" (1979, p. 228).

Das positivas valoracións que lle merecen López Ferreiro, Otero e, en certa forma, tamén Risco despréndese a alta consideración que Carballo tiña das funcións metahistórica e ideolóxica do xénero narrativo, consideración que -como veremos- está detrás da relevante posición que lle outorga ao primeiro no canon literario galego e tamén doutros intereses que manifesta ao final da súa andaina crítica, como o que lle inspiran, por exemplo, as novelas de Víctor Freixanes (Carvalho 1989). 
Xa que logo, confeso que non teño claro ata que punto a reticente actitude de CC fronte á novela era resultado dos prexuízos que sempre amosou cara á narrativa coma un xénero menor fronte á poesía (e que, polo tanto, debía reforzarse cun plus ideolóxico ou, cando menos, informativo) ou, ao contrario, ese tipo de consideracións xurdían un tanto paradoxalmente dunha concepción do xénero tan sumamente moderna que canxaba mal coa produción narrativa galega máis convencional. A seguir, tentarei dilucidar esta cuestión partindo das dúbidas que o propio CC manifestaba en 1975:

Con lo que ha venido a ser la novela en los tiempos modernos, apenas es posible asegurar lo que es y, por lo tanto, si lo es, algún producto literario en que lo narrativo, lo descriptivo o lo discursivo se interfieren en combinaciones diversas [...] en que medida puede [la novela] tolerar la competencia de otras formaciones expresivas, cual es el margen de seguridad que distingue la novela lírica de la lírica, o la novela ensayo del ensayo, son cuestiones arduas en las que no caben dogmatismos (Carballo 1975, p. 60).

CC manifesta aquí unha fundada intuición do carácter inevitablemente híbrido e proteico da novela moderna ou, pola contra, ve nesa mesma natureza un argumento máis para desconfiar dunha modalidade textual que sempre resultara problemática no caso galego? O certo é que Don Ricardo mantivo sempre, en relación ao xénero narrativo, esta tensión dialéctica que iría alimentando con novos argumentos fornecidos pola evolución do sistema literario galego xa dende data tan temperá (verémolo máis adiante) como a década dos 50 . Estoume a referir ao recoñecemento do papel que o público lector empezaba a xogar no desenvolvemento da literatura galega, unha mudanza necesaria mais que para CC non se producirá sen danos colaterais, como veremos.

Para CC, o rexurdir da narrativa galega a partir dos 50 débese ao feito de que:

la hegemonía de la poesía lírica que había dominado desde sus orígenes la literatura gallega cede antes las tendencias didácticas y realistas que impone la prosa. Aun en el terreno de la invención fantástica, el público reclamará el asidero de la cotidianeidad de la forma, que con la expresión prosística le proporciona una ilusión de seguridad que neutraliza o corrige teóricamente la estampida temática. Cunqueiro poeta es suplantado por Cunqueiro prosista. La poesía se disfraza de prosa para subsistir, y esta desnaturalización acaba por desautorizarla. El público preferirá la prosa al verso prosaico (Carballo 1975, p. 61). 
Detrás destas consideracións alenta a pobre opinión que ao Carballo crítico literario lle merecían determinadas propostas poéticas do momento, mais non é iso o que nos interesa agora senón dous argumentos que o crítico manexa en estreita relación: un, que o auxe da "prosa" non se debe tanto a méritos propios das novas modalidades narrativas como ao que el denomina "a desnaturalización" da poesía; dous, que nese pulo ten moito que ver a demanda do público lector, unha demanda que-como veremos-, Carballo avogará por atender pro domo sua.

\section{LIBROS E AUTORES GALEGOS: O RECOÑNECEMENTO DA AUCTORITAS CANONIZADORA DO CRÍTICO}

Unha atención singular para a nosa análise merecen os dous volumes publicados baixo o título común Libros e autores galegos, non só polo evidente interese do seu contido senón tamén porque o propio autor insinuou a posibilidade de consideralos como unha sorte de prolongación da súa HLG, e así o manifesta no limiar: "Do moito disperso que sobre a materia podía arrecadarse, parecéu conveniente espigar o que segue, o que en certo xeito cabe contemplar como un complemento da Historia da literatura galega contemporánea" (Carballo 1982, p. 3). O primeiro abrangue "dos trovadores a Valle-Inclán", e así figura no subtítulo; o segundo está dedicado ao "século XX". Na miña opinión, nesta recolleita de estudos CC desprega o mellor do seu talento crítico e analítico. Antes de dedicar a algúns deles unha máis demorada atención, quero determe primeiro nalgunhas cuestións editoriais relacionadas con esta obra. Publicada pola Fundación Pedro Barrié de la Maza, Conde de Fenosa, a edición foi responsabilidade da Real Academia Galega, que con esta obra daba inicio á colección Galicia viva. No limiar ao tomo I, publicado en 1979, o daquela presidente da institución, Domingo García-Sabell, gaba -na mellor tradición retórica do xénero prologal- a figura e a obra de CC e nunha grandilocuente laudatio enumera os diferentes trazos do perfil intelectual nos que se alicerza a autoridade de Don Ricardo; unha "autoridade que ninguén lle pode discutir" e que se sustenta no feito de ser "na actualidade o historiador e o valorador do noso corpo literario que suscita máis confianza, que consigue máis seguidores e que ten a virtude de sentar doctrina”. Esta convicción xa aparece reiteradamente exposta por Piñeiro nas cartas que lle envía a CC na década dos 50, como un dos argumentos principais cos que tenta -e consegueconvencelo de que asuma a responsabilidade de redactar o que finalmente sería a súa HLG. Vinte e cinco anos despois, as palabras de García-Sabell amosan que CC seguía a ser o intelectual que gozaba de máis capital simbólico e maior poder canonizador no ámbito da literatura galega, de aí que non só fose determinante o que dicía senón tamén aquelo que non dicía ou ignoraba. Vexamos, a través do 
amplo abano de textos recollidos nestes dous volumes, como o profesor exercía tal potestade no xénero que agora nos ocupa.

Dos 42 textos recollidos no volume I de Libros e autores galegos, só hai tres propiamente dedicados a un novelista: Antonio López Ferreiro. Con isto o ilustre cóengo queda implicitamente consagrado como a gran figura da narrativa galega ata a aparición das personalidades estelares da Xeración Nós. Certamente, a esta consideración contribúe de xeito notable o feito de que cultivase a novela his-

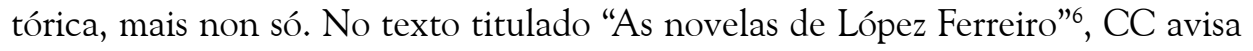
de que non cometamos o erro de crer "que as novelas de López Ferreiro carezan de atractivo literario" (Carballo 1979, p. 237) para, a seguir, analizar gabanciosamente o seu estilo, a construción de personaxes e a súa fortuna na creación de ambientes populares. Pero, sobre todo, Don Ricardo albisca algo que as seguintes achegas críticas á obra narrativa do cóengo semellan esquecer ou ignorar. Refírome á relación que esta mantén cun conxunto de textos que o historiador da literatura española José Luis Alborg etiqueta como 'novela histórica regional' e que Carballo define máis matizadamente como "novela romántica de asunto local e tradicional" (1979, p. 232). Inaugurada en galego, xa un tanto serodiamente, por Don Antonio, fora cultivada con certo éxito en castelán por autores galegos como Benito Vicetto ou Bernardo Barreiro de Vázquez Varela. Estamos a falar dunha produción que exalta os valores tradicionais (cos que tan ben sintonizaba o noso cóengo) así como a historia e costumes propiamente galegos, ao tempo que se vencella a obras semellantes que apareceran dende mediados do século XIX noutros contextos periféricos coma o vasco-navarro, nunha coincidente dinámica creativa que pode ser interpretada en boa medida como un xeito de oposición ao centralismo literario español ${ }^{7}$.

Xa que logo, alén dos méritos lingüísticos e literarios que CC recoñece nas novelas de López Ferreiro, coido que ao establecer este vencello xenealóxico do corpus do cóengo cunha xerarquía narrativa que ten como máis ilustres representantes a Otero e Castelao, o profesor está a facer valer como -quizais máximo?factor canonizador a eficaz explotación que estes tres autores fan do potencial que o xénero narrativo ten para analizar uns factores identitarios, que evidentemente non serán sempre os mesmos posto que cada momento histórico e cada autor irán poñendo o foco nos que consideren máis operativos social e/ou politicamente. Como o propio CC recoñece explicitamente, "sempre tiveron unha necesaria repercusión sobre as obras literarias as circunstancias políticas que rodean o escri-

\footnotetext{
6 É o que xa publicara na HLG, cun breve engadido feito ad hoc, en 1978 para o limiar á edición de O niño de pombas editado polo Departamento de Filoloxía Galega da Universidade de Santiago de Compostela como homenaxe co gallo do Día das Letras Galegas.

7 Desenvolvo estas ideas por extenso en Vilavedra (2005).
} 
tor" (Carballo 1982, p. 376) e "é difícil imaxinarse unha novela que non sexa social" (Carballo 1982, p. 377).

Vaiamos agora co tomo II, sen dúbida de maior interese para nós, e empecemos polo índice. Este revela, en primeiro lugar, que CC segue a operar (igual que acontecía na HLG) co par opositivo poesía / prosa que tan funcional lle resultara sempre e, polo tanto, apostando por un criterio máis formalista ca inmanente. En segundo lugar, o índice pon de manifesto con rotundidade o seu canon autorial, no que de novo ocupan unha posición senlleira Castelao, Otero e Risco. Deteñámonos, de entrada, nestes e comecemos polo rianxeiro. Nesa altura do seu percurso intelectual, a altísima valoración que a obra de Castelao lle merece a CC (quen o manterá sempre, como xa vimos, no cume do canon) explícase por ser "fundamentalmente un cultivador da forma breve, e mesmo da brevísima" (Carballo 1982, p. 52) que é a base do "carácter épico-lírico" das Cousas e, en maior ou menor medida, de toda a narrativa de Castelao (1982, p. 53); ao lirismo cómpre engadirlle o humorismo (1982, p. 53) e con isto xa temos activado o trío de vectores canónicos que xa coñecemos. De aí que cando CC busca unha obra coa que equiparar as Cousas, a electa sexa Cantares, "como testemuño artístico e delucidación psicolóxica das clases populares" (1982, p. 55) pois, como ben aclara o profesor, o esforzo despregado con anterioridade por Lamas Carvajal de crear "unha prosa descritiva e narrativa [...] que glosara as formas contemporáneas da vida popular" acadou "unha representación moi calificada do campesino" mais carente de "ese halo poético que nimba as figuras de Castelao" (1982, p. 62).

É dicir, Carballo desaproveita a oportunidade que lle ofrecía a escolma Libros e autores galegos (como outras que irá publicando nos anos seguintes, de menos impacto canonizador, na miña opinión) para compensar o evidente protagonismo que na HLG posúe a poesía fronte á narrativa; protagonismo explicable, como xa vimos, polas súas propias conviccións en relación á xerarquía de xéneros literarios galegos mais tamén polo espectro histórico que abrangue a Historia (recordemos que a partir da 3 a edición se lle engade ao título a especificación cronolóxica 1808-1936) e tamén pola filiación evidente que hai entre ela, a súa tese de doutoramento e as obras derivadas desta ${ }^{8}$. E desaproveita esa oportunidade malia recoñecer nas novas voces narrativas elementos que chaman a súa atención e valora positivamente, como veremos.

8 Por unha banda, unha sorte de prototipo galego do que sería a tese, publicado por Galaxia en 1955 co título Sete poetas galegos, onde estudaba a obra de Rosalía de Castro, Curros Enríquez, Pondal, Noriega, Cabanillas, Luis Amado Carballo e Manuel Antonio; por outra, xa directamente derivada da tese case homónima, ese mesmo ano aparece en Gredos Aportaciones a la literatura gallega contemporánea onde, ao estudo dos poetas e da poeta citados, CC engade o de dous prosistas: Castelao e Otero. 
En definitiva, en Libros e autores galegos, obra fulcral na súa traxectoria, o Carballo crítico non é quen de distanciarse da súa concepción da historia literaria como procedemento de ordenación dunha xerarquía autorial (Casas 2020, p. 179), é dicir, de formulación dun canon. No relativo á narrativa, o extenso labor crítico de Carballo non modificará a súa proposta canónica inicial nin os criterios nos que a sustentou sempre, malia algunhas certeiras intuicións, propias dun crítico experimentado, que -como veremos- manifestou contra o final da súa andaina e que parecían anunciar un posible cambio de rumbo nas súas preocupacións e prioridades estéticas, algo que se pon tamén en evidencia na resolución formal pola que opta para a súa derradeira novela, Scórpio (1987).

\section{UN CERTO CAMBIO DE RUMBO?}

Deteñámonos logo a comentar algúns dos devanditos criterios. Nas primeiras etapas do seu labor crítico, CC enfróntase co xénero narrativo moi condicionado polo problema da lingua, problema que como creador el evitara habilmente -por solución enunciativa, argumento, espazo e tempo- en A xente da Barreira. Na xa citada entrevista que en 1955 lle fai Salvador Lorenzana en Galicia emigrante, Carballo amósase atrapado entre o que el considera as demandas estéticas do seu tempo e as limitacións que a verosemellanza lingüística lle impuña daquela ao xénero:

Unha novela se non escribe tan doadamente como un tomo de poemas superrealistas, existencialistas ou neorrealistas. Pra facer versos distas crases abonda moitas veces a ousadía. Unha novela se non argalla tan impunemente [...] iqué cras de novela habería que facer? Xa temos novelas escelentes que refrexan a vida do campo no século dazanove. $O$ interesante sería hoxe unha novela de ambiente rigorosamente contemporáneo. Unha novela en galego que descrebise a vida das cidades, que falan en castelán inon resultaría un tanto forzada? E si se trata das crases inferiores, ihabería que reproducir o seu bárbaro bilingüismo ou poñerlles na boca a fala de Airas Nunes? O tarreo máis firme é a novela histórica e a novela rural.

[...]

habería que facer a novela de Prisciliano, a de Orosio, a de Etheria, a das grandes figuras e intres da nosa vella historia, pero percurando non caír no tipo de folletín. Habería que intentar tamén a novela lírica, psicolóxica ou naturalista de certos ambientes populares: a pequena vila peixeira, os pegureiros de alta montaña, os mineiros; en fin, todos os grupos aos que non resultara inevitabremente artificioso facerlles empregar a nosa lingoa (Lorenzana 1955, pp. 4-5). 
Como vemos, as solucións que CC propón son ben a autolimitación autorial a ambientes e épocas nas que o uso do galego resultase natural (ou sexa, a solución por el adoptada en A xente da barreira), ben o recurso á novela histórica como un territorio onde se produce de xeito natural a suspension of disbelief, o que explica a boa predisposición que amosou sempre cara ás obras adscribibles a esa modalidade xenérica, dende as fundacionais de López Ferreiro ata as de Víctor Freixanes (Carballo 1989b), pasando por Amantia de M. Xosé Queizán.

Pois ben, vinte anos despois, CC amosaríase disposto, aínda que sen grande entusiasmo, a matizar esta consideración:

Hoy puede considerarse superado el prejuicio fotográfico y después de novelas como Si o vello Sinbad volvese ás illas [...] no se hallarán muchos novelistas que no se muestren dispuestos a aceptar que la lengua de la novela puede imponer su ley al diálogo de los personajes (Carballo 1975, p. 60).

Á vista desta evolución resulta pertinente formularmos a cuestión de ata que punto as preferencias estéticas de CC, no relativo ao xénero narrativo, estiveron condicionadas polos seus prexuízos lingüísticos ou ben por outra caste de prexuízos que resultaron determinantes no escaso entusiasmo crítico manifestado ante obras de indiscutible orixinalidade e calidade de autores como Cunqueiro ou, sobre todo, Blanco Amor, orixinalidade e calidade que o Don Ricardo analista non deixaría de recoñecer mais sen deixar de confesar ao tempo unha tépeda adhesión persoal.

En carta a Piñeiro do 10 de setembro de 1956 CC manifestaba a seguinte opinión d'As crónicas do sochantre:

[o libro] gañaría con que o autor houbera sido un pouco máis mirado no emprego de verbas groseiras. O "groseiro" é de por sí antiestético; e non hai inxenio capaz de unxir de beleza o refugallo fecal [...] A miña repugnancia refírese únicamente aos termos ou alusións direitamente relacionados coas funcións fisiolóxicas máis elementás. Non creo que a cortesía na linguaxe sexa só recomendable pra colexialas de colexios de monxas; senón que é unha conquista da cultura moderna [...] Paso por que haxa licencias de linguaxe ao falar das relacións secsuás [...] Mais confeso humildemente que non me fan gracia ningunha as referencias literarias aos fenómenos de dixestión i eliminación dos alimentos (Alonso e Cochón 2015, p. 117).

Aquí Don Ricardo defende o criterio do decoro (o termo é seu) como discriminatorio á hora de adxudicar un maior ou menor valor estético a unha obra. Pois 
ben, case tres décadas máis tarde (en 1980), CC permanecía fiel á súa reivindicación do decoro, tal e como revela ao fío do seu comentario d'A nosa cinza de Alcalá:

Hai autores que parecen gozarse na ruptura das normas do decoro, como se o decoroso fose reaccionario, ou feminino, ou burgués, ou supersticioso. Eu coido que o decoro é unha exixencia da dignidade humana. E que o indecoroso é indigno da plena humanidade (Carballo 1982, p. 378).

Na miña opinión, este foi o elemento que resultou determinante do seu distante posicionamento perante a produción narrativa de Blanco Amor, do que tanto se leva falado e sobre o que formularei algunhas breves consideracións. En primeiro lugar, cómpre aclarar que, malia o vitimismo das queixas do ourensán, en xeral as opinións de CC sobre a súa obra non foron abertamente desfavorables? No caso de Blanco Amor, coido eu que CC disfraza de análise lingüística o que son meros prexuízos ideolóxicos, tanto no relativo á moral coma á manifestación dun certo clasismo. Véxanse como exemplos os cualificativos de "elemental e groseiro" que lle apón ao galego do Castizo ou que considere a lingua da novela como "vulgar e caracterizada polo seu primitivismo" (Carballo 1982, pp. 192-193).

Sobre a polémica recepción e fortuna editorial de Xente ao lonxe, coñecemos sobre todo a versión do propio autor, quen en reiteradas ocasións lle atribue á Real Academia Galega a responsabilidade de que a novela fose derrotada por Adiós, María no Premio Galicia convocado polo Centro Gallego de Buenos Aires en 1970:

esta novela, Xente ao lonxe, se presentó a un concurso, y los mismos académicos que la habían votado por unanimidad para ocupar un sillón en la Real Academia Gallega la rechazaron de plano, la novela, porque era una novela procaz, es decir, una novela mal hablada ${ }^{10}$ (Blanco Amor 1994, p. 118).

Velaquí, efectivamente, outra volta o famoso criterio do decoro. Neste caso Blanco Amor fala con coñecemento de causa pois, no informe emitido por un dos membros do xurado, Leandro Carré, este axuíza a obra como "un relato férido, esfalazado, unha godalleirada, que por respeito aos lectores non consideramos axeitado para sere acetado neste certame" (Blanco Amor 1994, p. 118).

9 Sobre esta cuestión véxase Dasilva (2020), quen si interpreta os comentarios do profesor como manifestacións dunha valoración ben negativa.

10 Esta convicción aparece xa manifestada polo propio Blanco Amor no seu limiar a Xente ao lonxe (1972). 
Certamente, Carballo non formaba parte do xurado mais, sen dúbida, esta sentencia encaixa como unha luva coas opinións que sobre a obra manifestou en diversas ocasións e mesmo chegaría a recoñecer, dun xeito un tanto oblicuo, que a novela de Blanco Amor fora "rexeitada unanimemente por unha sorte de discriminación moral” (Carballo 1981, p. 717). Por outra banda, non sería de estrañar que algúns membros do xurado, compañeiros académicos menos experimentados nas lides da lectura crítica, consultaran a CC (por aquel entón máximo experto de literatura do grupo Galaxia) á hora de resolveren un certame no que a obra do ourensán competía cunha novela de Xohana Torres, unha escritora moza abeirada ao devandito grupo e que fora alumna de Carballo nos tempos de Ferrol. Naturalmente, tanto ela coma el (Bermúdez 2011, pp. 28-29) rexeitaron calquera sospeita de favoritismo mais resulta inverosímil, no reducido e proteccionista ambiente literario da época, que algúns membros do xurado non intuísen de quen podía ser a novela que finalmente resultou galardoada.

Alén da polémica, o que nos interesa dela é constatar ata que punto detrás da derrota de Xente ao lonxe estaba a operar o famoso decoro co que sen dúbida tan ben sintonizaba CC e que explica a súa fría acollida tanto desta novela coma d'A esmorga, unha frialdade manifestada non tanto de xeito explícito coma, diriamos, 'por omisión', pois o profesor evitou calquera tratamento que puidese redundar na incorporación das obras do ourensán ao canon e aos circuítos nos que este se configuraba.

O certo é que CC dedicou escasa atención á narrativa galega de Blanco Amor e, cando o fixo, semella que foi por compromiso (Dasilva 2020). Non o cita nos artigos panorámicos que lle poñen o ramo ao segundo volume de Libros e autores galegos, asinados respectivamente en 1974 e 1975. Nin o menciona nunha conferencia (tamén de enfoque panorámico) impartida en Coimbra en 1971 (logo recollida como artigo en Carballo 1974). Porén, si aparece entre os autores seleccionados no seu Breviario antológico de la literatura gallega (1966), unha obra que segundo confesa o propio antólogo na súa introdución, amosaba "escritores que ya están indiscutiblemente incorporados por la prueba del tiempo a nuestra historia literaria" (Carballo 1966, p. 8). A profesionalidade do crítico Carballo conseguía embridar os seus prexuízos e incluír o ourensán nesta galería canónica, aínda que a obra escolleita fose Os biosbardos (obviamente, menos orixinal e complexa cás novelas galegas dos autor), da que se ofrece o final do primeiro relato, un dato que fala por si mesmo e que pon de manifesto, unha vez máis, a incomodidade que a Don Ricardo lle producía A esmorga. Esta incomodidade revélase outra volta na selección de fragmentos de textos blancoamorianos que o profesor inclúe no volume 2 da súa triloxía Prosa galega (subtitulado Dos novecentistas aos nosos días) 
e publicado en 1978: un d'A escadeira de Jacob, outro d'Os biosbardos e dous de Xente ao lonxe; sorprendentemente, ningún d'A esmorga.

Na miña opinión, o seu escaso entusiasmo ante a produción narrativa de Blanco Amor (especialmente ante A esmorga) non ten tanto que ver con cuestións de forma - pois CC non eludiu recoñecer certos méritos do novelista ${ }^{11}$ - coma de fondo ${ }^{12}$. Que non se trataba do primeiro amósao a súa boa disposición como crítico a acoller as novidades técnicas ou formais: velaí a súa positiva valoración de Adiós María e, en xeral das obras da Nova Narrativa Galega. Xa en 1961 CC recoñecía, nunha recensión sobre $O$ crepúsculo e as formigas, que "A narrativa galega contemporánea está a se renovar gracias aos esforzos de algúns escritores mozos que se amosan ben garnecidos no que se refire aos recursos técnicos da novelística moderna" (Carballo 1982, p. 356).

Da novela de Xohana Torres CC diría o seguinte (Carballo 1974, p. 75):

es el esfuerzo más sostenido que se ha realizado para lograr una novela gallega cuya composición y fraseo le den un aspecto moderno en el sentido de que su sintaxis narrativa la agrupe en el conjunto de novelas europeas y americanas cuya técnica consiste en el cruce constante de elementos.

En 1975 escribía o seguinte en relación ás novelas da logo chamada Nova Narrativa Galega que definía como:

novelas intelectuales, de composición deliberadamente 'nueva' o 'revolucionaria' [...] son ante todo forma, son ante todo artesanía, son ante todo literariedad. Y, por supuesto, productos absolutamente indigeribles para el público sin ilustración al que, según las declaraciones de algunos escritores actuales, se debe consagrar todo esfuerzo de comunicación que la literatura comporta. Felizmente, el público ilustrado también tiene derecho a leer, y ello justifica este tipo de literatura (Carballo 1975, p. 75).

11 "A esmorga, no momento en que se publicóu, supuxo unha novedade na literatura galega" (HLG, p. 716) ou "A esmorga é unha concienzuda esproración dun ambiente prácticamente descoñecido na literatura galega, ao que se quer dar espresión auténtica mediante a ficción dun narrador que ten tal ambiente como atmósfera natural, e que non posee máis horizonte que aquel que o mesmo ambiente baña" (Carballo 1981, p. 717).

12 A modo de exemplos, véxanse afirmacións coma "non se desprega en A esmorga un sentido esplícito de símbolo ético [...] non se ouserva unha intención inmediata de sinificación trascendente" (Carballo 1981, p. 717) ou "A evidente propensión deste narrador a presentar en toda a súa crueza situacións de miseria moral e física, sen pararse en barras na reproducción da fala popular, amósanolo como un adepto do naturalismo, e carece de relevancia para fundamentar unha concepción sociolóxica ou filosófica” (HLG, p. 718). 
A mediados dos 70 o Carballo crítico leva xa tempo tentando incorporar ao seu discurso os ecos que sen dúbida lle estaban a chegar das correntes da socioloxía e a semiótica literarias, que poñían o foco da análise na esfera da recepción. E nesa evolución interveñen, unha vez máis, os prexuízos do Carballo individuo que se cruzan coa súa pericia crítica ata o punto de entraren en colisión no desenvolvemento do seu labor, como xa vimos que sucedía no caso de Blanco Amor.

Efectivamente, CC é ben consciente da importancia que a demanda do público lector ten no desenvolvemento das literaturas modernas. Xa en 1963 avogaba por atender esa demanda, mais faino cun argumentario non exento do clasismo ao que xa me referín. CC recoñece que "o público leitor repártese en moitos estratos, e só as capas superiores son permeabeis á literatura artística de alto rango" e, a seguir, afirma que "nunha colectividade cultural autárquica compre satisfacer a demanda de todos os grupos de leitores" (Carballo 1982, p. 393). Pero cal é a razón que sustenta esta reivindicación? Pois unha concepción xerárquica e elitista do canon, que se constrúe como unha pirámide a cuxo cume só teñen acceso os seres electos: "non se comprende a esistencia dunha literatura selecta, dirixida aos intelectuáis, sin supór por baixo dela unha serie de actividades literarias escalonadas, que sustentan e xustifican históricamente a actividade superior" (Carballo 1982, p. 393). A partir de aquí, CC desenvolve neste artigo unha afervoada defensa avant la lettre do que sería un dos obxectivos prioritarios do sistema literario galego nos 80: a novela popular sexa - como el di- rosa, de misterio, de aventuras ou, sobre todo, policíaca. Ata aquí, nada que obxectar ao fino olfacto analítico do profesor, que ventaría cun par de décadas de antelación unha necesidade que a crítica dos 80 presentou coma se fose o descubrimento da pólvora: a ampliación da oferta narrativa como paso previo ao aumento do público lector, o que semellaba imprescindible para a supervivencia da literatura galega na democracia capitalista. Mais si quero poñer en evidencia o elitismo que subxace no seu argumentario, que fala por si mesmo:

O disfrute de certas refinadas belezas esixe un certo capital intelectual. $\mathrm{O}$ número de leitores en galego debe ampliarse mediante o fomento dunha literatura popular, que satisfaga as modestas esixencias das persoas de mediana ilustración. Aínda que esto importe pouco á arte, importa, e moito, á hixiene social. Só unha xenerosa abundancia de literatura barata pode sustentar con seguridade a esistencia dunha literatura cara (Carballo 1982, p. 394).

A súa reivindicación dunha narrativa popular non obedecía pois a un afán dunha maior democracia cultural senón á preocupación por garantir o dereito da minoría ilustrada a poder consumir produtos axeitados á súa demanda. E por 
iso CC defende con tanta simpatía os autores da Nova Narrativa Galega. Porque as súas obras son o que el considera "alta literatura" dirixida a unha "aristocracia intelectual": a do lector de literatura galega que, segundo el, é nese momento "o leitor máis culto de Galicia” (Carballo 1982, p. 393). Unha vez máis, os prexuízos ideolóxicos de CC -de clase, neste caso- determinan o seu criterio estético.

\section{1. O CASO MOURULLO}

Na miña opinión, a polémica que tentou abrir Mourullo, a partir dos comentarios publicados por CC en La Noche sobre Terra brava de Fole (obra, segundo o xove narrador, moito mellor valorada polo crítico que as súas Memorias de Tains) permite ver con claridade, e como xa se apuntou, ata que punto a evolución natural do seu agudo criterio literario o inclinaba a entender e valorar a obra dos autores máis novos, mais tamén como nesa evolución se mantivo fiel a algúns dos principios estéticos e socioliterarios cos que se achegara sempre á narrativa galega.

Non vou debullar a polémica, que pode reconstruírse ${ }^{13}$ moi ben a partir das cartas que sobre o asunto intercambian Piñeiro e Carballo (Alonso e Cochón 2015, pp. 150-154), centradas na "Carta a Manuel Antonio" publicada por Mourullo en La Noche o 26 de xaneiro de 1957. Nela o narrador amósase (sen citalo directamente) moi molesto con dous $\operatorname{artigos}^{14}$ de CC nos que este -supostamente e sempre segundo Mourullo- é incapaz de ver a orixinalidade das Memorias de Tains e de reparar no europeísmo da obra, para rematar acusando ao crítico de pasatista por non ver ata que punto a súa literatura -a de Mourullo- recollía con intensidade os problemas da época. O desmesurado ego de Mourullo impídelle ponderar con xusteza a opinión que a CC lle merece Terra brava, que eu non cualificaría de particularmente laudatoria pois a recensión remata aludindo aos "problemas que plantea o libro de Fole" (Carballo 1982, p. 242) que para o crítico se resumen nun, non menor, "o da dosificación na súa obra do documental e o artístico" (Carballo 1982, p. 242). Isto, despois de debullar no seu comentario a "forte preocupación didáctica da obra” (Carballo 1982, p. 240), que é posible sexa "para moitos leitores demasiado ostensíbel" (1982, p. 240).

O que a Mourullo parece molestarlle é que CC aluda abertamente á influencia de Kafka nos seus contos, que diga que escribe "só para intelectuáis" (Carballo 1982, p. 349) e que "fai literatura de laboratorio, literatura esperimental", animándoo a "saír do laboratorio" e "botarse á rúa” (metaforicamente, claro está).

13 Tamén dá pistas, e o seu particular punto de vista, Xosé Luís Franco Grande n’Os anos escuros. A resistencia cultural dunha nación (2004). Unha interpretación máis político-ideolóxica do caso atópase en A nación incesante. Conversas con Xosé Manuel Beiras (2000).

14 "Sobre Terra brava" e "Kafka, Faulkner e outros kas", recollidos no tomo II de Libros e autores galegos. 
Ante isto, para Mourullo semella non valer nada que gabe o "talento positivo" (Carballo 1982, p. 348) do novo e "ameno narrador" e a "simpatía" da súa primeira obra, Nasce un árbore. Coido eu que, como primeira acollida, estes cordiais cualificativos non están nada mal. Tentando ser obxectiva, coido que nin a CC lle enche tanto o ollo Fole nin lle desgusta tanto Mourullo. Porque, en definitiva, o que a el de verdade lle gustan son "as fórmulas menos radicais: a fórmula do conto de Castelao, menos primitivo que o de Fole; a fórmula do conto de Otero, menos elaborado que o de Mourullo" (Carballo 1982, p. 349).

Alén dos detalles da polémica, esta nos interesa - unha vez máis- como mostra dun Carballo non mal disposto a acoller as novidades, por moi radicais que fosen, aínda que non renunciase a xulgalas coa súa vara de medir habitual. $\mathrm{O}$ problema era que Castelao e Otero puñan o listón moi alto.

\section{A MODO DE CONCLUSIÓNS}

A preferencia de CC polas formas narrativas breves foi unha constante no seu labor crítico e estivo sempre estreitamente relacionada coas singularidades sociohistóricas do nacemento e desenvolvemento do xénero narrativo e da clara secundarización á que someteu este, en comparación coa poesía.

Non debemos ignorar, á hora de orientar os seus criterios canonizadores, o peso dos elementos identitarios sinalados dende Nós como característicos da cultura galega e que Carballo subscribiu explicitamente durante boa parte da súa andaina profesional. Se en 1955 declaraba que "Las dotes más aparentes del gallego, musicalidad, ternura y expresividad, impulsaron hacia el verso a los primeros escritores" (Carballo 1985, p. 11), a musicalidade segue a estar-como xa vimos-detrás da altísima valoración que lle merecen, por exemplo, as Cousas de Castelao, e aínda en 1980 recoñecía como un factor merecente de alta valoración o lirismo dunha novela longa coma A nosa cinza (Carballo 1982, p. 378).

Como xa se apuntou tamén, a comparación con Otero e Castelao lle serviu sempre como criterio avaliador e canonizador de obras e autores. Por exemplo, na HLG di: "Dieste lembra a Castelao. Humor, lirismo, ambiente temático, acabado da obra, importancia da conclusión: todo esto é común a ambos rianxeiros" (Carballo 1981, p. 713). Mais isto non significa que CC non fose consciente das carencias e hipertrofias da nosa literatura e que, consonte isto, non fose quen de evoluír e facer evoluír o seus criterios canonizadores: en data tan temperá como 1956 xa lle escribía a Piñeiro, en confianza, "a soberana potencia lírica de Otero é, en certo xeito, unha desgracia porque domina a un autor que, sen isa inclinación, houbera sido o gran épico da terra galega. E hoxe a terra galega ten máis necesidade de épicos que de líricos" (Alonso e Cochón 2015, pp. 139-140). 
Xa vimos como Carballo foi adquirindo unha maior conciencia da natureza híbrida e proteica da novela moderna, o que alimentaría a relación dialéctica, entre desconfiada e admirativa, que sostivo cunha modalidade textual que sempre resultara problemática no caso galego. Esa relación, que mantivo ao longo de toda a súa vida, foise sustentando en novos argumentos que revelan un crítico atento ás achegas das novas correntes teóricas pero tamén á propia evolución da sociedade literaria que produce e consume o seu obxecto de estudo. Estoume a referir, sobre todo, á atención que Carballo lle prestou dende data moi temperá á necesidade de atender as demandas do público lector, o que lle serve de argumento base para unha reivindicación da novela policial claramente precursora ${ }^{15}$ da que xurdiría no sistema literario galego dos 80 .

Porén, cómpre non esquecer que é a funcionalidade xerárquica e discriminatoria que para Carballo ten o canon literario o que sustenta esa reivindicación (e, en xeral, a súa defensa dunha narrativa popular). Porque, en última instancia, é esa mesma concepción a que explica a súa incomodidade perante a narrativa de Blanco Amor ou a súa simpatía pola Nova Narrativa Galega. A actuación canonizadora de Carballo, no relativo á narrativa galega, estivo sempre mediatizada polos seus prexuízos (históricos, lingüísticos, identitarios, ideolóxicos...) mais coido que, máis a miúdo do que se adoita recoñecer, foi quen de superalos ou, máis ben, integralos no seu punto de vista para achegarse aos textos dende unha perspectiva inmanente, deixándonos análises que aínda hoxe resultan iluminadoras e -diría eu-imprescindibles. Velaí, como exemplos a citar de entre os moitos que se poderían ofrecer, os seus comentarios das novelas de Cunqueiro ou de Xente ao lonxe en 1975.

\section{REFERENCIAS BIBLIOGRÁFICAS}

Alonso Girgado, Luís e Cochón, Luís (eds.) (2015). Epistolario Ricardo Carballo Calero-Ramón Piñeiro (Historial dun libro). Cadernos Ramón Piñeiro XXXIII. Santiago de Compostela: Centro Ramón Piñeiro para a Investigación en Humanidades.

Bermúdez, Teresa (2002). Unha lectura de Adiós María de Xohana Torres. Vigo: Edicións Xerais de Galicia.

Blanco, Carmen (1989). Conversas con Carballo Calero. Vigo: Galaxia.

15 Véxanse os artigos "O case Leavenworth" e "A novela policíaca", ambos datados en 1963 (recollidos en Carballo 1982, pp. 392-397). 
Blanco Amor, Eduardo (1994). O oficio de escritor. En: Victoria Álvarez Ruiz de Ojeda, ed. Entrevistas con Blanco Amor. Vigo: Nigra, 101-122.

Casas, Arturo (2020). Carvalho Calero e a historia literaria: idea, institucionalización e procedementos. En: Francisco Cidrás, ed. Ricardo Carvalho Calero. As formas do compromiso. Santiago de Compostela: Universidade de Santiago de Compostela, 167-205.

Dasilva, Xosé M. (2020). Carballo Calero, xuíz d'A esmorga. Grial, 58 (227), 90-99.

Franco Grande, Xosé L. (2004). Os anos escuros. A resistencia cultural dunha nación. Vigo: Galaxia.

Lorenzana, Salvador (1955). Á fala con Carballo Calero sobre temas da nosa cultura. Galicia emigrante, 16, 4-5.

Pillado Maior, Francisco e Fernán-Vello Miguel A. (2000). A nación incesante. Conversas con Xosé Manuel Beiras. [Santiago de Compostela]: Laiovento; [A Coruña]: Espiral Maior.

Piñeiro, Ramón (1959). Factores esenciales de la literatura gallega. Ínsula, 152 $153,12$.

Vilavedra, Dolores e Saavedra, Pegerto (2005). Introdución histórico-literaria. En: Antonio López Ferreiro, O castelo de Pambre. Santiago de Compostela: Sotelo Blanco.

\section{Obras citadas de Ricardo Carballo Calero:}

Carballo Calero, Ricardo (1955). Aportaciones a la literatura gallega contemporánea. Madrid: Gredos.

Carballo Calero, Ricardo (1966). Breviario antológico de la literatura gallega. [A Coruña]: Real Academia Gallega.

Carballo Calero, Ricardo (1971). Sobre lingua e literatura galegas. Vigo: Galaxia.

Carballo Calero, Ricardo (1974). Figuras representativas da literatura galega actual. Grial, 45, 269-279.

Carballo Calero, Ricardo (1975). La novela gallega actual. Revista de la Universidad Complutense, 24(99), 59-80.

Carballo Calero, Ricardo (1979). Libros e autores galegos. Dos trovadores a Valle-Inclán. A Coruña: Fundación Pedro Barrié de la Maza.

Carballo Calero, Ricardo (1981). Historia da literatura galega contemporánea. 3ª ed. Vigo: Galaxia.

Carballo Calero, Ricardo (1982). Libros e autores galegos. Século XX. A Coruña: Fundación Pedro Barrié de la Maza. 
Carballo Calero, Ricardo (1989). Estudos e ensaios sobre literatura galega. Sada: Ediciós do Castro.

Carvalho Calero, Ricardo (1983). Da fala e da escrita. Ourense: Galiza editora. Carvalho Calero, Ricardo (1989). Ensaios sobre narrativa galega de após-guerra. Agália, 20, 419-433.

Carvalho Calero, Ricardo (1990). Do galego e da Galiza. Sada: Ediciós do Castro. Carvalho Calero, Ricardo (1992). Umha voz na Galiza. [Barcelona]: Sotelo Blanco. 